\title{
Erratum to Analysing the Expert Judgment of a Rehabilitation Counsellor: A Case Study
}

\author{
James A. Athanasou \\ University of Technology, Australia
}

The purpose of this short note is to report an error in Athanasou and Kaufmann (2010) Table 4 (p. 81). This was noted when preparing data for a comparison in a follow-up study. Data columns for the predictive accuracy of a cue and the predictive accuracy of a judgement were inadvertently transposed by the first author. The probability of each cue correctly identifying the quality of life and the rehabilitation counsellor's judgement are now summarised in Table 1.

The revised results for Table 4 indicate that using any one of five cues would have provided the expert with at least $54 \%$ accuracy in correctly identifying the quality of life and not $83.7 \%$ as indicated. Instead satisfaction with personal relationships was used most $(83.7 \%)$ of the time by the counsellor and by itself had a $62 \%$ probability of correctly identifying whether quality of life was rated as good or poor.

The overall conclusion (2010, p. 82) of the paper remains unchanged, namely that the counselling expert in the study was correct in $64.8 \%$ of cases and displayed clinical judgment accuracy but that a simpler decision-making heuristic could still have been used. As noted in the article at page 78, the complete dataset still remains available upon request and any inconvenience is regretted.

\section{Reference}

Athanasou, J.A., \& Kaufmann, E. (2010). Analysing the expert judgment of a rehabilitation counsellor: A case study. Australian Journal of Rehabilitation Counselling, 16(2), 73-84.

\section{TABLE 1}

Revised Table 4 - Probability of a Cue Correctly Indicating the Quality of Life or Judgment ( $N=37$ cases)

\begin{tabular}{lcc}
\hline Cue & $\begin{array}{c}\text { Probability of a cue } \\
\text { indicating Quality of Life }\end{array}$ & $\begin{array}{c}\text { Probability of a cue } \\
\text { indicating a judgement }\end{array}$ \\
\hline Health & .59 & .73 \\
Energy & .54 & .68 \\
Daily activities & .59 & .62 \\
Self-satisfaction & .62 & .84 \\
Personal relationships & .62 & .70 \\
Money & .59 & .57 \\
Living conditions & .59 & .57 \\
\hline
\end{tabular}

Note: Quality of life was rated as good $45.9 \%$, or as poor $54.0 \%$. 